\title{
Treatment by polyacrylicacid and chitosan on silk
}

\author{
E.Saraswathi ${ }^{1}$, J.Jeyakodi Moses ${ }^{2}$ \\ \{esaraswathi2021@gmail.com, jjmoses2k2@gmail.com ${ }^{1}$ \}
}

Bharathiar University, Ph.D. Research Scholar, Research \& Development Centre, Coimbatore 641046, India, ${ }^{2}$ PSG College of Technology ${ }^{1}$, Associate Professor, Department of Applied Science, Coimbatore 641004, India ${ }^{2}$.

\begin{abstract}
The important valuable protein based natural fiber silk contains lot of eminent characteristics such as textile / garment performances, bio applications, aesthetic comfort aspects, sheen shine. Due to the sensitive and delicacy aspects of silk, it is often possibly attacked by different sources, hence it is vital to protect silk from the damages come from chemicals, lights, and insects. Therefore, this research work gives an attempt to give resistance on silk by treating it with the simple chemicals like polyacrylicacid (PAD) and chitosan $(\mathrm{CSN})$ and then coloration with some natural sources and a reactive synthetic dye. The silk fabrics after these treatments are tested for color values, fastness properties, physical properties, absorbency characters, anti-odor effects, SEM study and XRD study. The output of these tests give very useful improvement in the results applicable in the protection considerations suitable for silk fabric products.
\end{abstract}

Keywords: Silk, PAD, CSN, SEM, XRD

\section{Introduction}

The natural filamentous fiber silk is mainly proposed for the important values of surface softness \& shining, durability \& drapeability, aesthetics \& comforts. Silk is mostly consumed in India based on the fancy characteristics; and accordingly India is the second largest producer of the mulberry silk next to China (1,2). In 2017, 1,42,000 tonnes of silk was produced by China, whereas India produced only 32,000 tonnes. The special properties of silk give the uniqueness to it. The specific gravity of $1.25-1.3 \mathrm{~g} / \mathrm{cm} 3$ is present silk filament with the cross section in triangular shaped. There is no scales on the surface of silk filament makes it so smooth and lustrous; contains the tenacity of $0.38 \mathrm{~N} /$ tex and elongation at break $23.4 \%$ under the standard conditions of $65 \%$ relative humidity at $20^{\circ} \mathrm{C}(3-5)$. Moreover, the most sensitive fiber mulberry silk could be easily damaged by insects, light \& chemicals in the severe conditions, and hence the protection of which is very important that shall be increased by some soft chemical applications(6,7). An anionic polyelectrolyte Polyacrylicacid (PAD) is similar to polyvinylalcohol with the considerable degree of ionization is dependent on the respective $\mathrm{pH}$ of the solution. The most high available polymers in nature, after cellulose, Chitosan (CSN) is a bio-polymer and a chitin acetylated product developed as the byproduct in the processing industries of sea-food. The important valuable characteristics of chitin is also predominantly present in chitosan namely, biodegradable, highly absorbing capacity, notoxic \& bio-compatibilty (8-10). By considering these aspects, in this research work, the polyacrylicacid (PAD) and chitosaan (CSN) are selected and applied on the silk fabric, and further dyed with some listed ecofriendly 
colorants and a reactive synthetic dye. The silk fabric samples, after these treatments were undergone for some required tests like physical property measurement, $\mathrm{k} / \mathrm{s} \&$ fastness property study, absorption checking, anti-odor effect finding, and morphological analysis. The output of the results is highly convincing suitable to the silk end use products.

\section{Experimental}

\subsection{Materials}

The silk (100\%, mulberry, plain fabric) was purchased in Sharvodhaya Sang-Vadavalli, Coimbatore, TamilNadu, India. The Coimbatore forest department, TamilNadu, India provided the natural color agents (Table-A). The Commercial shop in Thiruupur, TamilNadu provided the synthetic dye (reactive)(Table-A). The Scientific company in coimbatore, TamilNadu provided the Polyacrylicacid (PAD); and the cochin refineries company, kerala, India provided the commercial chitosan(CSN). All the auxiliaries \& chemicals specified somewhere in this work are used as the analytical level.

Table-A. Silk (mulberry) fabric and natural color agent details

\begin{tabular}{|l|l|}
\hline S.No. & Silk (mulberry) fabric - details \\
\hline 1.0 & Warp : $2 / 80^{\text {s count }}$ \\
\hline 2.0 & Weft : $2 / 80^{\text {s count }}$ \\
\hline 3.0 & Ends / inch: 100 \\
\hline 4.0 & Picks / inch: 60 \\
\hline 5.0 & Gsm : 95 \\
\hline 6.0 & Cloth width: 44inch \\
\hline S.No. & Natural color agents - Details \\
\hline 1.0 & Crocus sativa (Kum kum) : Yellow \\
\hline 2.0 & Berberis vulgaris (Bar berry) : Yellow \\
\hline 3.0 & Bixa orellana (Annatto) : Orange \\
\hline 4.0 & Allium cepa (Onion) : Red Orange \\
\hline 5.0 & $\begin{array}{l}\text { Pterocarpus } \text { santallinus } \text { (Red } \\
\text { sandalwood) : Orange Red }\end{array}$ \\
\hline 6.0 & Citrus paradise (Grape) : Purple \\
\hline 7.0 & Rubia cardifolia (Madder) : Red \\
\hline 8.0 & $\begin{array}{l}\text { C.I. Name:Reactive yellow } \text {-135 (Reactive } \\
\text { yellow HE6G) : Yellow }\end{array}$ \\
\hline
\end{tabular}




\subsection{Method}

\section{2-1. Silk fabric for degum process}

The pretreatment was carried out on silk fabric using HCl-hydrochloric acid (condition; 10 gpl, 60 minutes, room temperature, MLR 1:30) in order to get rid of the natural and added impurities. Degum process was carried out on this pre-treated silk fabric using $\mathrm{Na}_{2} \mathrm{CO}_{3}-$ sodium carbonate $(2 \% \mathrm{owm}) \&$ degum detergent $(1 \% \mathrm{owm})$ (condition : temperature $85^{\circ} \mathrm{C}$, Two hours, MLR 1:30) by the standard method stated as before. $(11,12)$.

\subsubsection{Silk fabric for Polyacrylicacid treatment}

The polyacrylic acid (PAD) with the strength of $0.5 \% \mathrm{w} / \mathrm{v} ; 1 \% \mathrm{w} / \mathrm{v} ; 1.5 \% \mathrm{w} / \mathrm{v} ; 2 \% \mathrm{w} / \mathrm{v}$; $2.5 \% \mathrm{w} / \mathrm{v} ; 3.0 \% \mathrm{w} / \mathrm{v} ; 3.5 \% \mathrm{w} / \mathrm{v} ; 4 \% \mathrm{w} / \mathrm{v} ; 4.5 \% \mathrm{w} / \mathrm{v} ; 5 \% \mathrm{w} / \mathrm{v} ; 5.5 \% \mathrm{w} / \mathrm{v} ; \% 6.0 \% \mathrm{w} / \mathrm{v}$ in alkaline sodium hydroxide solution $(0.25 \mathrm{~N})$ was subjected on silk fabric for thirty min. Then the fabric samples are padded for squeezing, drying by $105^{\circ} \mathrm{C}$, thirty min, \& cured at the temperature of $140^{\circ} \mathrm{C}$, sixty sec. After that the fabric samples were thorough washed, dried and taken for the further treatments. (13).

\subsubsection{Silk fabric for chitosan treatment}

By $2 \%$ acetic acid solution, the CSN (chitosan) was dissolved $[15,16]$, filtered and considered as the standard solution for the required treatments. In a specified bath, the needed concentration of the solution was taken with MLR1:30. In the specified CSN bath, the silk fabric samples were immersed. By maintain the $\mathrm{pH}$ at 5.0 \pm 0.2 with acetic acid. Further the bath temperature is increased to $95^{\circ} \mathrm{C}, \&$ kept of thirty minutes. Then the fabric samples are ready for used after the normal washing and drying (14-16).

\subsubsection{Silk fabric for dyeing and $\mathrm{k} / \mathrm{s}$ value measurement}

The silk samples applied for dyeing (concentration of $25 \mathrm{gpl}$, natural dyes \& $2 \%$ owm, synthetic dyes) at nearly boiling temperature (two hours, MLR 1:20) by the standard method as stated earlier $(17,18)$.

\subsubsection{Dyed silk fabric for fastness property study}

The dyed silk fabric samples were tested for the wash fastness property by IS 764-test 3-1979 method; light fastness property by AATCC test method 16E-2004; crocking fastness property by AATCC test method 8-2007; and AATCC standardized crock meter was used to find out the wet $\&$ dry rubbing fastness of the dyed silk fabric samples (19-22).

\subsubsection{Silk fabric for physical property measurement}

For the testing of physical properties of the silk fabrics, the established standard techniques were used $(23,24)$. 


\subsubsection{Silk fabric for absorbency test}

The absorbency tests were conducted in the treated and dyed silk fabrics as per the standard techniques (25-29).

\subsubsection{Silk fabric for antiodor behavior study}

The silk fabrics (treated, dyed and finished - antiodor finishing agent H9000) were subjected for antiodor behavior study by the standard method as stated earlier $(30,31)$.

\subsubsection{Silk fabric for SEM study}

The silk fabric was subjected for SEM analysis as per the standard procedures $(32,33)$.

\subsubsection{Silk fabric for XRD study}

The silk fabric sample was subjected for the XRD analysis to get know the unknown crystalline components present, by the known standard technique (Shimadzu XRD6000) $(34,35)$

\subsection{Results and Discussion}

\subsection{Fundamental properties of silk}

The fundamental physical properties of the mulberry silk with no treatment, PAD treatment and CSN treatment are given in Table-1 and the corresponding data after dyeing on the silk fabric are given in Table 1-a. The silk fabrics with PAD and CSN treatments are given according to the trials carried out for the confirmation of time and concentration. The mulberry silk fabrics were treated earlier with PAD and CSN of the concentration originated by $0.5 \% \mathrm{w} / \mathrm{v}$ to $6.0 \% \mathrm{w} / \mathrm{v}$ with varied time duration from five minutes to sixty minutes by the step of five. The PAD and CSN treatments were optimized on silk fabric samples to give the reasonable results by the duration of thirty minutes. 
Due to this, the concentration of $0.5 \% \mathrm{w} / \mathrm{v}$ to $6.0 \% \mathrm{w} / \mathrm{v}$ of PAD and CSN was optimized to apply on the silk fabric with the duration of 30 minutes for all the treatments and the respective data are shown in the Table-1. It is observed that from the table-1, as the concentrations of PAD and CSN applications on the silk fabric increases correspondingly the physical properties also increases. The known factor is that the material under tensile stress in the great deformation of uniform material stresses; considered to be the tensile strength. There is a substantial increase in the tensile strength of PAD and CSN treated silk fabrics when compared to that of the one without these applications.

In the case of warp and weft sides of (PAD \& CSN treated) silk fabric, there is an average of nearly $8 \%$ and $10 \%$ increase of the tensile strength compared with the untreated one. The warp strength shows drastic increase over that of the corresponding weft side of the PAD and CSN treated silk fabric. It is observed that, as the concentration of PAD and CSN increases, there is a remarkable improvement in the tensile strength in both the warp and weft ways upto only $4 \%(\mathrm{w} / \mathrm{v})$, then the increase is very narrow. With regard to that of $\%$ elongation among the PAD, CSN and no treated silk fabrics, there is only marginal difference which is by the level of around only 3\%. Elongation - due to stretching in a textile fiber is considered to be the increase in deformation or length. In the case of drape coefficient there is only $1.0 \%$ average decrease which reveals that the drape coefficient of the silk fabric is not influenced after the PAD and CSN treatment, It is understood that the way of a fabric hangs under its own weight considered to be mentioned as drape. There is no considerable impact in the thermal resistances of the (PAD and CSN treated) silk fabrics which is almost in the values around $98\left(\mathrm{~m}^{2} . \mathrm{mk} / \mathrm{w}\right)$ in most of the cases. In connection to the clothing comfort, the facts of thermal characteristics is believed important because there is direct relationship between comfort and thermal characteristics. There is around one fold increase in the bending modulus values of the PAD and CSN treated silk fabrics compared to that of the untreated one by the stiffness tests that measures the bending stiffness of a fabric by allowing a narrow strip of the fabric to bend to a fixed angle under its own weight. The fabric is in general considered to be stiffer when the bending length is more. Based on the data in the Table-1, the values in the physical property of the silk fabrics applied with PAD and CSN, there is a remarkable difference till the concentration is upto $4 \%(\mathrm{w} / \mathrm{v})$, then afterwards, the change is not significant. Therefore the treatment on the silk fabric using PAD and CSN is optimized using the strength of $4 \%(\mathrm{w} / \mathrm{v})$ for thirty minutes. For further works also, this condition is selected and utilized.

The mulberry silk fabrics were dyed after the PAD and CSN treatments (4\%-w/v, 30-minutes) using some selected natural dyes and a yellow synthetic reactive dye. Subsequently, the physical properties were studied in the corresponding manner and the values are given in the Table 1-a. Similar to the Table 1, there is a similar trend of values available in the Table 1-a also. By comparing with the values of PAD and CSN treated and dyed silk fabrics, the difference is remarkable only in the case of the untreated silk fabrics. Insignificant difference in the physical properties is available when compared between the PAD and CSN treated dyed silk fabrics, 
Table1. Fundamental properties of PAD and CSN treated silk fabric

\begin{tabular}{|c|c|c|c|c|c|c|c|c|c|}
\hline \multirow{2}{*}{\multicolumn{2}{|c|}{$\begin{array}{l}\text { Testing Parameters on } \\
\text { Silk Fabric }\end{array}$}} & \multicolumn{8}{|c|}{ Concentration of Chemicals ( PAD \% w/v) } \\
\hline & & 0.0 & 0.5 & 1.0 & 2.0 & 3.0 & 4.0 & 5.0 & 6.0 \\
\hline \multirow{2}{*}{$\begin{array}{l}\text { Tensile Strength } \\
(\mathrm{Kgf} / \mathrm{mm} 2)\end{array}$} & warp & 55.1 & 58.15 & 58.24 & 59.17 & 58.56 & 61.15 & 61.26 & 61.39 \\
\hline & weft & 47.9 & 50.96 & 51.05 & 51.28 & 51.94 & 53.86 & 53.92 & 53.99 \\
\hline \multirow[t]{2}{*}{ Elongation (\%) } & warp & 16.7 & 16.6 & 16.6 & 16.2 & 15.8 & 15.0 & 14.9 & 14.8 \\
\hline & weft & 15.8 & 15.7 & 15.6 & 15.3 & 14.9 & 14.0 & 13.9 & 13.8 \\
\hline \multicolumn{2}{|l|}{ Drape Co-efficient } & 0.68 & 0.676 & 0.676 & 0.675 & 0.674 & 0.670 & 0.670 & 0.669 \\
\hline \multicolumn{2}{|l|}{$\begin{array}{l}\text { Thermal resistance } \\
\left(\mathrm{m}^{2} . \mathrm{mk} / \mathrm{w}\right)\end{array}$} & 98.9 & 98.86 & 98.81 & 98.70 & 98.48 & 97.86 & 97.81 & 97.79 \\
\hline \multicolumn{2}{|c|}{$\begin{array}{l}\text { Stiffness / Bending modulus } \\
\text { value }\end{array}$} & 0.0014 & 0.0015 & 0.0015 & 0.0016 & 0.0016 & 0.0020 & 0.0022 & 0.0023 \\
\hline \multirow{2}{*}{\multicolumn{2}{|c|}{$\begin{array}{l}\text { Testing Parameters on Silk } \\
\text { Fabric }\end{array}$}} & \multicolumn{8}{|c|}{ Concentration of Chemicals (CSN \% w/v) } \\
\hline & & 0.0 & 0.5 & 1.0 & 2.0 & 3.0 & 4.0 & 5.0 & 6.0 \\
\hline \multirow{2}{*}{$\begin{array}{l}\text { Tensile Strength } \\
(\mathrm{Kgf} / \mathrm{mm} 2)\end{array}$} & warp & 55.1 & 60.65 & 60.84 & 61.57 & 61.96 & 63.75 & 63.87 & 63.98 \\
\hline & weft & 47.9 & 53.08 & 53.25 & 53.58 & 54.24 & 56.16 & 56.25 & 56.31 \\
\hline \multirow[t]{2}{*}{ Elongation $(\%)$} & warp & 16.7 & 16.0 & 15.6 & 15.6 & 15.2 & 14.4 & 14.3 & 14.2 \\
\hline & weft & 15.8 & 15.1 & 15.0 & 14.7 & 14.3 & 13.4 & 13.3 & 13.2 \\
\hline \multicolumn{2}{|l|}{ Drape Co-efficient } & 0.68 & 0.68 & 0.672 & 0.670 & 0.667 & 0.658 & 0.657 & 0.657 \\
\hline \multicolumn{2}{|l|}{$\begin{array}{l}\text { Thermal resistance } \\
\left(\mathrm{m}^{2} . \mathrm{mk} / \mathrm{w}\right)\end{array}$} & 98.9 & 98.9 & 98.79 & 98.68 & 98.45 & 97.82 & 97.79 & 97.78 \\
\hline \multicolumn{2}{|c|}{$\begin{array}{l}\text { Stiffness / Bending modulus } \\
\text { value }\end{array}$} & 0.0014 & 0.0014 & 0.0017 & 0.0017 & 0.0018 & 0.0022 & 0.0023 & 0.0023 \\
\hline \multicolumn{10}{|c|}{ Time : 30 minutes } \\
\hline
\end{tabular}

Table 1-a. Fundamental properties of PAD and CSN treated dyed silk fabric

\begin{tabular}{|c|c|c|c|c|c|c|c|c|c|c|}
\hline \multicolumn{3}{|c|}{$\begin{array}{c}\text { Natural Coloring } \\
\text { Sources } \rightarrow\end{array}$} & \multirow[t]{2}{*}{ (i) } & \multirow[t]{2}{*}{ (ii) } & \multirow[t]{2}{*}{ (iii) } & \multirow[t]{2}{*}{ (iv) } & \multirow[t]{2}{*}{ (v) } & \multirow[t]{2}{*}{ (vi) } & \multirow[t]{2}{*}{ (vii) } & \multirow[t]{2}{*}{ (viii) } \\
\hline & ffect on Silk Fabri & $\downarrow$ & & & & & & & & \\
\hline \multirow{3}{*}{ NO } & \multirow{2}{*}{$\begin{array}{c}\text { Tensile Strength } \\
\text { (Kgf/mm2) }\end{array}$} & Warp & 58.35 & 58.76 & 58.54 & 58.47 & 58.68 & 58.59 & 58.62 & 58.78 \\
\hline & & Weft & 51.09 & 51.37 & 51.15 & 51.14 & 51.18 & 51.15 & 51.17 & 51.39 \\
\hline & Elongation (\%) & Warp & 15.9 & 15.2 & 15.3 & 15.1 & 15.2 & 15.4 & 15.3 & 15.6 \\
\hline
\end{tabular}




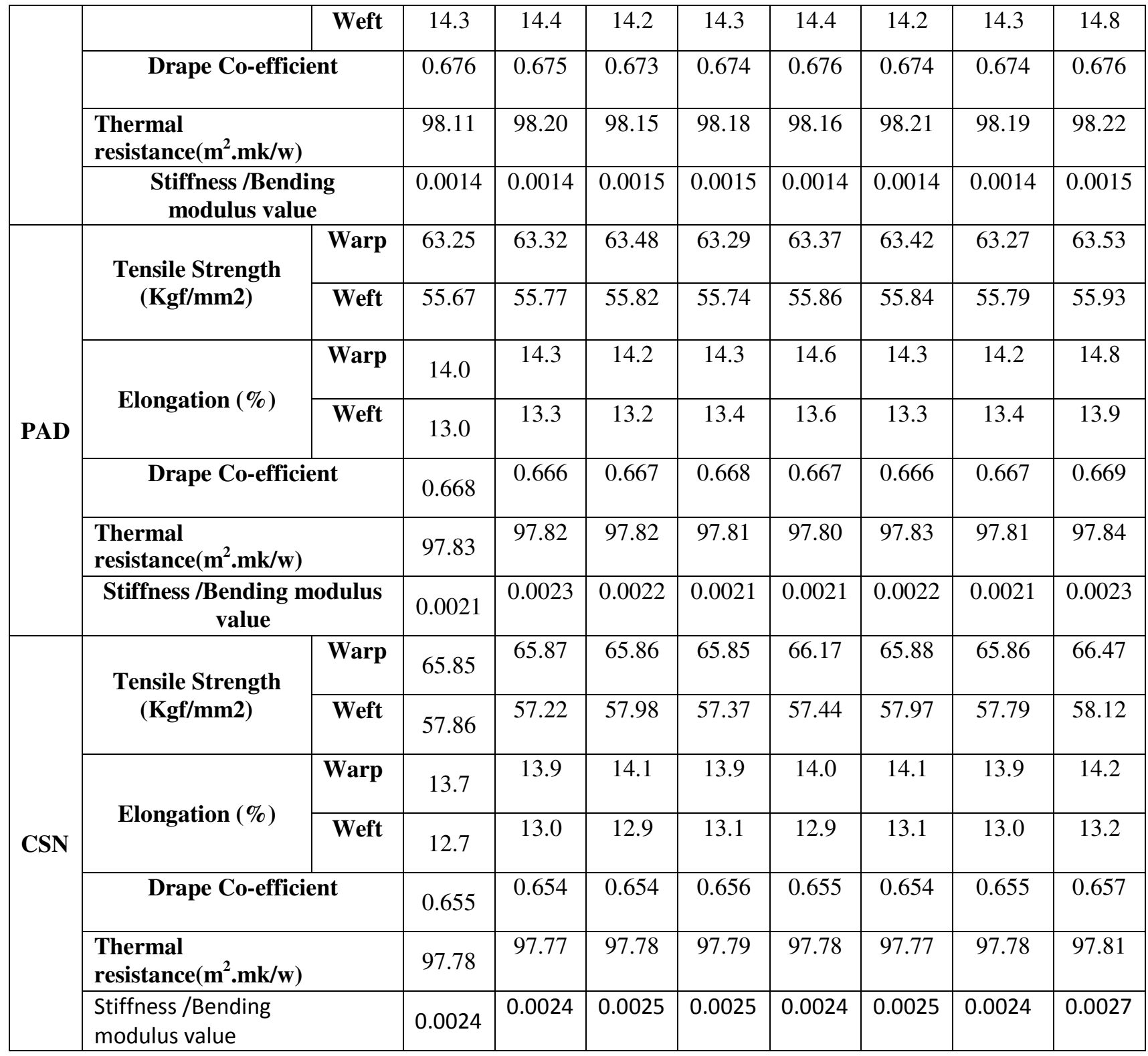

\subsection{K/S-color values and the color fastness Property}

The k/s-color values and the respective color fastness properties of the mulberry silk fabrics subjected with PAD and CSN followed by the dyeing with natural colorants and a synthetic 
reactive dye are shown in the Table-2. The corresponding results for the no treatment dyed mulberry silk fabrics were also provided for comparison. It is observed from this table that there is a considerable improvement in the dyeing effect on the CSN treated dyed silk fabric on comparison with the PAD treated and no treatment dyed mulberry silk fabrics. It is evident that the increased may be by the interaction of the functional groups involved between the dyes and the CSN molecules. The CSN treated and dyed silk fabric shows increased values compared to the respective PAD treated one. Similarly, this effect is influenced in the corresponding fastness properties also as visible in the Table-2. The CSN \& PAD treated dyed silk fabrics show the maximum fastness property values with respect to washing, light and rubbing compared to that of the no treated dyed silk fabrics which show the least one in all the categories.

Table-2. K/S-color value and color fastness property of the PAD and CSN treateddyed silk fabric

\begin{tabular}{|c|c|c|c|c|c|c|c|c|c|c|}
\hline \multicolumn{3}{|c|}{ Natural Coloring Sources $\rightarrow$} & (i) & (ii) & (iii) & (iv) & (v) & (vi) & (vii) & (viii) \\
\hline \multicolumn{3}{|c|}{ Effect on Silk Fabric $\quad \downarrow$} & & & & & & & & \\
\hline \multirow{5}{*}{ NO } & \multicolumn{2}{|c|}{ K/S values } & 12.6 & 12.5 & 12.9 & 13.2 & 12.2 & 11.7 & 12.8 & 13.5 \\
\hline & \multicolumn{2}{|c|}{ Washing fastness } & 3 & $2-3$ & 3 & 3 & 3 & $2-3$ & 3 & $3-4$ \\
\hline & \multicolumn{2}{|c|}{ Light fastness } & 4 & $3-4$ & 4 & 4 & $3-4$ & 3 & 4 & $4-5$ \\
\hline & \multirow{2}{*}{$\begin{array}{l}\text { Rubbing } \\
\text { fastness }\end{array}$} & Wet & 2 & 2 & 2 & 2 & 2 & 2 & 2 & 2 \\
\hline & & Dry & 2 & $2-3$ & $2-3$ & 3 & 2 & $2-3$ & 3 & $2-3$ \\
\hline \multirow{5}{*}{ PAD } & \multicolumn{2}{|c|}{$\mathrm{K} / \mathrm{S}$ values } & 14.6 & 14.5 & 14.6 & 14.9 & 14.3 & 14.0 & 14.6 & 14.9 \\
\hline & \multicolumn{2}{|c|}{ Washing fastness } & 3 & 3 & 3 & $3-4$ & 3 & 3 & 3 & $3-4$ \\
\hline & \multicolumn{2}{|c|}{ Light fastness } & 4 & 4 & 4 & $4-5$ & 4 & $3-4$ & 4 & $4-5$ \\
\hline & \multirow{2}{*}{$\begin{array}{l}\text { Rubbing } \\
\text { fastness }\end{array}$} & Wet & $2-3$ & 2 & $2-3$ & $2-3$ & 2 & $2-3$ & 3 & 2 \\
\hline & & Dry & 3 & 3 & $3-4$ & 3 & 3 & $3-4$ & $3-4$ & 3 \\
\hline \multirow{5}{*}{ CSN } & \multicolumn{2}{|c|}{$\mathrm{K} / \mathrm{S}$ values } & 14.7 & 14.5 & 14.7 & 14.9 & 14.5 & 14.3 & 14.7 & 14.9 \\
\hline & \multicolumn{2}{|c|}{ Washing fastness } & 3 & 3 & $3-4$ & $3-4$ & 3 & 3 & $3-4$ & 4 \\
\hline & \multicolumn{2}{|c|}{ Light fastness } & $4-5$ & 4 & $4-5$ & 5 & 4 & 4 & 4 & $5-6$ \\
\hline & \multirow{2}{*}{$\begin{array}{l}\text { Rubbing } \\
\text { fastness }\end{array}$} & Wet & $2-3$ & $2-3$ & $2-3$ & $2-3$ & $2-3$ & $2-3$ & 3 & $2-3$ \\
\hline & & Dry & $3-4$ & $3-4$ & $3-4$ & $3-4$ & $3-4$ & $3-4$ & $3-4$ & 3 \\
\hline
\end{tabular}




\subsection{Absorbency effect of the PAD and CSN treated mulberry silk fabric}

The absorbency effect of the mulberry silk fabric treated with PAD and CSN followed by dyeing with natural colorants and a synthetic reactive dye is shown in Table-3. From this table, it is understood that there is a direct relationship for the absorbency effect in te silk fabric. It is seen that in the less time the PAD and CSN treated and dyed silk fabrics absorb the drops in comparison with the silk fabric of no treatment. In the same manner, there is an increase in the silk fabrics for the respective water retention behavior and the wicking height. With respect to the respective increase of drop absorbency and water retention; the wicking behavior is also high on the treated (PAD and CSN) and dyed silk fabrics. The silk fabric treated with CSN [and dyed (natural sources and reactive dye)] gives increased values for the effect of drop absorbency, water retention and wicking followed by the PAD treated one and no treatment and dyed one.

\begin{tabular}{|c|c|c|c|c|c|c|c|c|c|c|}
\hline \multicolumn{2}{|c|}{ Natural Coloring Sources $\rightarrow$} & \multirow{3}{*}{$\begin{array}{l}\text { (0) } \\
46\end{array}$} & \multirow{3}{*}{$\begin{array}{l}\text { (i) } \\
44\end{array}$} & \multirow{3}{*}{$\begin{array}{l}\text { (ii) } \\
45\end{array}$} & \multirow{3}{*}{$\begin{array}{l}\text { (iii) } \\
44 \\
\end{array}$} & \multirow{3}{*}{$\begin{array}{l}\text { (iv) } \\
43 \\
\end{array}$} & \multirow{3}{*}{$\begin{array}{l}\text { (v) } \\
45\end{array}$} & \multirow{3}{*}{$\begin{array}{l}\text { (vi) } \\
44\end{array}$} & \multirow{3}{*}{$\begin{array}{c}\text { (vii) } \\
44 \\
\end{array}$} & \multirow{3}{*}{$\begin{array}{r}\text { (viii) } \\
43\end{array}$} \\
\hline \multicolumn{2}{|c|}{ Effect on Silk Fabric $\quad \downarrow$} & & & & & & & & & \\
\hline \multirow{3}{*}{ NO } & Drop absorbency (sec) & & & & & & & & & \\
\hline & Water retention (\%) & 202 & 204 & 205 & 204 & 206 & 205 & 206 & 204 & 207 \\
\hline & Wicking (cm) [for 45 minutes] & 3.2 & 3.5 & 3.6 & 3.5 & 3.7 & 3.5 & 3.6 & 3.6 & 3.9 \\
\hline \multirow{3}{*}{ PAD } & Drop absorbency (sec) & 32 & 30 & 30 & 29 & 29 & 31 & 31 & 30 & 29 \\
\hline & Water retention (\%) & 224 & 229 & 227 & 228 & 227 & 227 & 227 & 228 & 229 \\
\hline & Wicking (cm) [for 45 minutes] & 6.1 & 6.3 & 6.4 & 6.4 & 6.6 & 6.5 & 6.4 & 6.5 & 6.8 \\
\hline \multirow{3}{*}{ CSN } & Drop absorbency (sec) & 29 & 27 & 27 & 26 & 25 & 26 & 25 & 26 & 25 \\
\hline & Water retention (\%) & 237 & 240 & 241 & 240 & 242 & 240 & 241 & 241 & 243 \\
\hline & Wicking (cm) [for 45 minutes] & 7.0 & 7.3 & 7.3 & 7.4 & 7.5 & 7.4 & 7.4 & 7.5 & 7.7 \\
\hline
\end{tabular}

Table3. Absorbency effect of the PAD and CSN treated mulberry silk fabric 


\subsection{Permeability effect (water vapor and air) in the silk fabric}

The permeability values (water vapor \&air)y of mulberry silk fabrics treated with PAD and CSN and dyeing with natural colorants and a synthetic reactive dye are given in the Table-4. Table-4 shows that after PAD and CSN applications and colorations with natural colorants and synthetic reactive dye, there is a linear increase in the permeability values (water vapor $\&$ air) as exposed by the silk fabrics. Also from this table that the water vapor permeability results are in connection with that of the air permeabilities of the mulberry silk fabric. Comparatively there is a high value for the mulberry silk fabrics applied with CSN and colored with the natural colorants and s synthetic dye in relation to the PAD treated and no treatment silk fabric.

Table-4. Permeability effect (Water vapor and air) in the silk fabric

\begin{tabular}{|c|c|c|c|c|c|c|c|c|c|c|}
\hline \multicolumn{2}{|c|}{ Natural Coloring Sources $\rightarrow$} & \multirow[t]{2}{*}{$(0)$} & \multirow[t]{2}{*}{ (i) } & \multirow[t]{2}{*}{ (ii) } & \multirow[t]{2}{*}{ (iii) } & \multirow[t]{2}{*}{ (iv) } & \multirow[t]{2}{*}{ (v) } & \multirow[t]{2}{*}{ (vi) } & \multirow[t]{2}{*}{ (vii) } & \multirow[t]{2}{*}{ (viii) } \\
\hline Effec & n Silk Fabric $\quad \downarrow$ & & & & & & & & & \\
\hline \multirow{2}{*}{ NO } & $\begin{array}{l}\text { Water Vapor Permeability } \\
\text { (g/m2/day) }\end{array}$ & 1578 & 1605 & 1610 & 1612 & 1615 & 1611 & 1612 & 1613 & 1624 \\
\hline & Air Permeability(1/min) & 72 & 76 & 77 & 78 & 80 & 78 & 77 & 79 & 83 \\
\hline \multirow{2}{*}{ PAD } & $\begin{array}{l}\text { Water Vapor Permeability } \\
\text { (g/m2/day) }\end{array}$ & 1646 & 1682 & 1687 & 1689 & 1690 & 1688 & 1687 & 1688 & 1700 \\
\hline & Air Permeability(1/min) & 75 & 82 & 83 & 85 & 86 & 84 & 83 & 85 & 88 \\
\hline \multirow{2}{*}{$\mathrm{CSN}$} & $\begin{array}{l}\text { Water Vapor Permeability } \\
(\mathrm{g} / \mathrm{m} 2 / \text { day })\end{array}$ & 1665 & 1707 & 1710 & 1712 & 1715 & 1712 & 1710 & 1711 & 1724 \\
\hline & Air Permeability(1/min) & 78 & 85 & 87 & 87 & 90 & 88 & 88 & 89 & 94 \\
\hline
\end{tabular}

\subsection{Effect of antiodor in PAD and CSN treated silk fabric}

The effect of the antiodor in the PAD and CSN treated silk fabric followed by dyeing with the natural colorants and a synthetic reactive dye is given in the Table-5. In order to do the assessment on the silk fabrics subjected for antiodor study; subjective evaluation technique was performed by six women of different age categories (25 to 50 years) and grading was rated between 0 and10. Accordingly, there is a marginal increase values for the CSN treated and colored fabrics compared to that of PAD treated and colored silk fabrics; meanwhile the average results of the effect of antiodor shown by the mulberry silk fabrics ranked by the judges are higher than eight. There is a ranking between the values of $7 \& 8$ for the silk fabric with no treatment and colored. In accordance with this context, it is revealed that the effect of antiodor in the mulberry silk fabric subjected with PAD \& CSN and colored with natural colorants and synthetic dye is high in a significant manner. 
Table5.Effect of antiodor in the PAD and CSN treated silk fabric

\begin{tabular}{|c|c|c|c|c|c|c|c|c|c|}
\hline \multicolumn{2}{|c|}{$\begin{array}{l}\text { Natural Coloring } \\
\text { Sources } \rightarrow\end{array}$} & (i) & (ii) & (iii) & (iv) & (v) & (vi) & (vii) & (viii) \\
\hline \multicolumn{10}{|c|}{ Effect on Silk Fabric $\downarrow$} \\
\hline \multirow{6}{*}{ NO } & $\mathbf{A}$ & 7 & 8 & 8 & 9 & 7 & 7 & 8 & 9 \\
\hline & B & 8 & 8 & 8 & 8 & 8 & 7 & 8 & 9 \\
\hline & C & 7 & 7 & 8 & 9 & 7 & 8 & 7 & 9 \\
\hline & D & 8 & 7 & 7 & 8 & 7 & 7 & 8 & 8 \\
\hline & $\mathbf{E}$ & 8 & 7 & 7 & 8 & 8 & 7 & 8 & 9 \\
\hline & $\mathbf{F}$ & 7 & 7 & 8 & 9 & 8 & 8 & 8 & 9 \\
\hline \multirow{6}{*}{ PAD } & $\mathbf{A}$ & 8 & 8 & 8 & 9 & 8 & 8 & 8 & 9 \\
\hline & B & 8 & 8 & 9 & 9 & 8 & 8 & 8 & 8 \\
\hline & C & 8 & 7 & 8 & 8 & 7 & 7 & 7 & 9 \\
\hline & D & 8 & 8 & 8 & 9 & 8 & 8 & 8 & 9 \\
\hline & $\mathbf{E}$ & 8 & 7 & 7 & 9 & 8 & 7 & 7 & 9 \\
\hline & $\mathbf{F}$ & 8 & 8 & 8 & 9 & 8 & 8 & 8 & 9 \\
\hline \multirow{6}{*}{ CSN } & $\mathbf{A}$ & 8 & 8 & 8 & 9 & 8 & 8 & 9 & 9 \\
\hline & B & 8 & 8 & 9 & 9 & 8 & 9 & 8 & 9 \\
\hline & C & 9 & 8 & 8 & 9 & 9 & 8 & 8 & 9 \\
\hline & D & 8 & 8 & 8 & 9 & 8 & 8 & 8 & 9 \\
\hline & $\mathbf{E}$ & 8 & 8 & 8 & 9 & 9 & 8 & 8 & 9 \\
\hline & $\mathbf{F}$ & 8 & 8 & 8 & 9 & 8 & 8 & 8 & 9 \\
\hline
\end{tabular}


A $\rightarrow$ Height $-162 \mathrm{~cm}$; Weight $-57 \mathrm{Kg}$, Age $\rightarrow 25$ years ; B $\rightarrow$ Height $-170 \mathrm{~cm}$; Weight $65 \mathrm{Kg}$, Age $\rightarrow 30$ years ; C $\rightarrow$ Height $-167 \mathrm{~cm}$; Weight $-70 \mathrm{Kg}$, Age $\rightarrow 35$ years ; D $\rightarrow$ Height - $66 \mathrm{~cm}$; Weight $-74 \mathrm{Kg}$, Age $\rightarrow 40$ years ; E $\rightarrow$ Height $-166 \mathrm{~cm}$;Weight-2 Kg, Age $\rightarrow 45$ years ; F $\rightarrow$ Height $-165 \mathrm{~cm}$; Weight- $78 \mathrm{Kg}$, Age $\rightarrow 50$ years

0 - Repulsive ； 1 - Very Poor; 2 - Poor ; 3 - Poorly Fair ; 4 - Fair ; $\quad$ - Acceptable ; 6 Fairly Good ； 7 - Good ～；8-Very Good ；9- Excellent ；10-Ideal

3.6 Influence of antiodor retention and release rate in the PAD and CSNtreated silk fabric

For the measurement of the strength of the antiodor agent, the extraction method is adopted in the finished mulberry silk sample by ethyl alcohol and used in the uv-visible spectrophotometer. With the help of the de-ionized water, the content of extract was diluted ten times; and taken for the measurement of absorbency at the wavelength of $206 \mathrm{~nm}$. After the required days, the effects related to antiodor (antiodor retention effect and antiodor release rate) exhibited by the mulberry silk fabrics treated with PAD and CSN and colored with natural colorants and synthetic reactive dye are presented in the Table-6. From this table, it is observed that there is a very good effect of antiodor retention rate in the PAD and CSN treated and colored silk fabrics specifically in the CSN treated silk fabrics in relation with that of the PAD and no treatment mulberry silk fabrics. In general, there is an average value difference of eight percent and sixteen percent with regard to the effect of antiodor release rate between the treated silk fabrics when compared for the original one and those after the four days and eight days time period in the respective silk fabric samples.

Table-6. Influence of antiodor retention and release rate in the PAD and CSNtreated silk fabric

\begin{tabular}{|c|c|c|c|c|c|c|c|c|c|c|}
\hline \multicolumn{3}{|c|}{$\begin{array}{l}\text { Natural Coloring Sources } \\
\rightarrow\end{array}$} & \multirow[t]{2}{*}{ (i) } & \multirow[t]{2}{*}{ (ii) } & \multirow[t]{2}{*}{ (iii) } & \multirow[t]{2}{*}{ (iv) } & \multirow[t]{2}{*}{ (v) } & \multirow[t]{2}{*}{ (vi) } & \multirow[t]{2}{*}{ (vii) } & \multirow[t]{2}{*}{ (viii) } \\
\hline Effe & t on Silk Fabr & $\downarrow$ & & & & & & & & \\
\hline \multirow{5}{*}{ NO } & \multirow{3}{*}{$\begin{array}{l}\text { Anti-odor } \\
\text { Retention } \\
\text { Effect (mg/g) }\end{array}$} & $\mathbf{A}$ & 312 & 310 & 312 & 314 & 311 & 310 & 312 & 316 \\
\hline & & B & 288 & 285 & 287 & 291 & 285 & 284 & 288 & 294 \\
\hline & & C & 257 & 255 & 257 & 262 & 256 & 254 & 258 & 266 \\
\hline & \multirow{2}{*}{$\begin{array}{l}\text { Anti-odor } \\
\text { Release Rate } \\
\text { Effect }(\%)\end{array}$} & $\mathbf{X}$ & 7.7 & 8.1 & 8.0 & 7.3 & 8.4 & 8.4 & 7.7 & 7.0 \\
\hline & & $\mathbf{Y}$ & 17.6 & 17.7 & 17.6 & 16.6 & 17.7 & 18.1 & 17.3 & 15.8 \\
\hline PA & Anti-odor & $\mathbf{A}$ & 328 & 327 & 328 & 330 & 327 & 326 & 328 & 332 \\
\hline
\end{tabular}




\begin{tabular}{|c|c|c|c|c|c|c|c|c|c|c|}
\hline \multirow[t]{4}{*}{ D } & \multirow{2}{*}{$\begin{array}{l}\text { Retention } \\
\text { Effect (mg/g) }\end{array}$} & B & 303 & 302 & 303 & 306 & 304 & 303 & 304 & 308 \\
\hline & & $\mathbf{C}$ & 274 & 274 & 275 & 278 & 276 & 274 & 276 & 280 \\
\hline & \multirow{2}{*}{$\begin{array}{l}\text { Anti-odor } \\
\text { Release Rate } \\
\text { Effect (\%) }\end{array}$} & $\mathbf{X}$ & 7.6 & 7.7 & 7.6 & 7.3 & 7.0 & 7.1 & 7.3 & 7.2 \\
\hline & & $\mathbf{Y}$ & 16.5 & 16.2 & 16.2 & 15.8 & 15.6 & 16.0 & 15.9 & 15.7 \\
\hline \multirow{5}{*}{$\begin{array}{l}\mathbf{C S} \\
\mathbf{N}\end{array}$} & \multirow{3}{*}{$\begin{array}{l}\text { Anti-odor } \\
\text { Retention } \\
\text { Effect (mg/g) }\end{array}$} & $\mathbf{A}$ & 346 & 345 & 346 & 350 & 346 & 345 & 346 & 353 \\
\hline & & B & 323 & 323 & 322 & 326 & 323 & 322 & 324 & 328 \\
\hline & & C & 298 & 297 & 298 & 302 & 298 & 297 & 299 & 305 \\
\hline & \multirow{2}{*}{$\begin{array}{l}\text { Anti-odor } \\
\text { Release Rate } \\
\text { Effect }(\%)\end{array}$} & $\mathbf{X}$ & 6.7 & 6.4 & 6.9 & 6.9 & 6.7 & 6.7 & 6.4 & 7.1 \\
\hline & & $\mathbf{Y}$ & 13.9 & 13.9 & 13.9 & 13.7 & 13.9 & 13.9 & 13.6 & 13.6 \\
\hline
\end{tabular}

Retention of anti odor agent : Immediately $\rightarrow$ A ; After 4 Days $\rightarrow$ B After 8 Days $\rightarrow$ C

Release rate of anti odoragent : After 4 Days $\rightarrow$ X ; After 8 Days $\rightarrow$

\subsection{Study from the SEM images of the PAD and CSNtreated silk fabric}

The SEM images of silk fabrics applied with PAD and CSN (1-a, 1-b) treatments followed by dyeing with natural dye, red sandal wood (RSW) (1c, 1d) respectively are given in the Figure1. In accordance to the effect of the PAD and CSN treatments on the silk fabrics, it is observed in the figure- 1 , that there is a clear difference as evidenced in these pictures. The SEM images exposed in the figures 1-a \& 1-b reveal about the impact of the effect of PAD and CSN treatment in the respective silk fabrics; meanwhile figures 1-c \& 1-d gives the clear indication about the SEM images of PAD and CSN treatment and RSW dyeing in the mulberry silk fabrics. From these SEM images, It is clear that there is a improved revelation in the appearance of the silk fabric treated with PAD \& CSN (Figures 1-a \& 1-b) and after coloration with RSW (Figures 1-c \& 1-d). Based on these considerations, it is clearly revealed that the effect of the application of the PAD \& CSN is significantly good in the mulberry silk fabrics; based on the capacity of the analysis performance of the locations in identified point in the samples by the implement of SEM - the image capacity of the microscope clarifies the specimen of the area interest. In that, for generating the number of signals at the surface of solid specimens; say textile samples, a clear beam of effective-energy electrons is used by the SEM instrument, for the reveal ofthe information based on the electron sample interactions with regard to the signals from the samples that include the surface morphology, materials orientation and also the crystalline structural aspects $(36,37)$. 


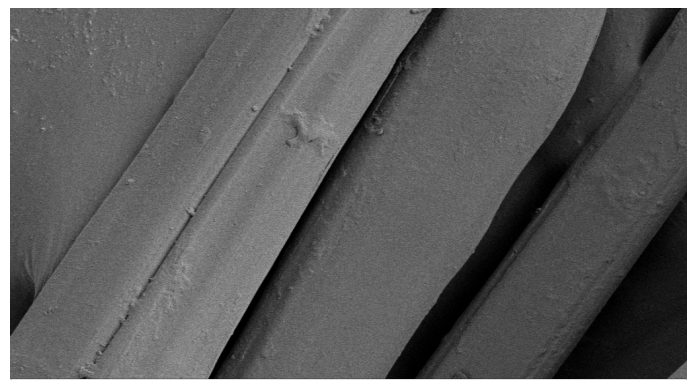

1-a. PAD treated silk fabric

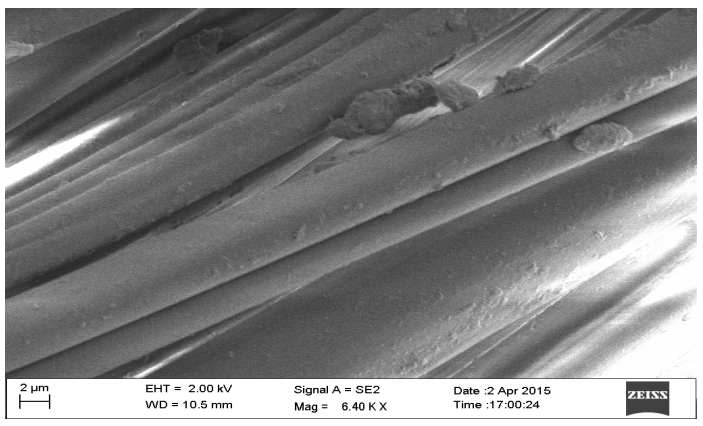

1-b. CSN treated silk fabric

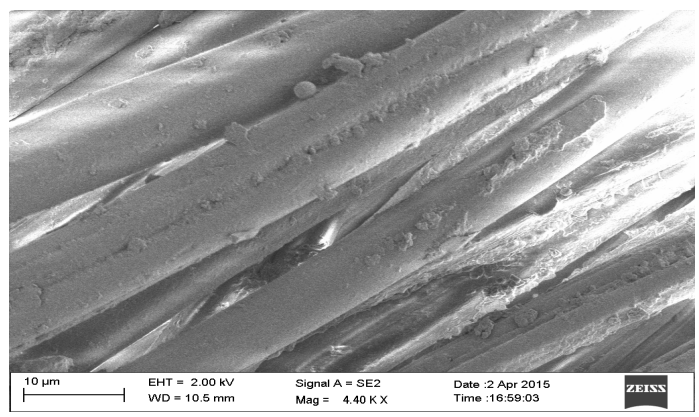

1-c. PAD treated \& RSW dyed silk fabric 


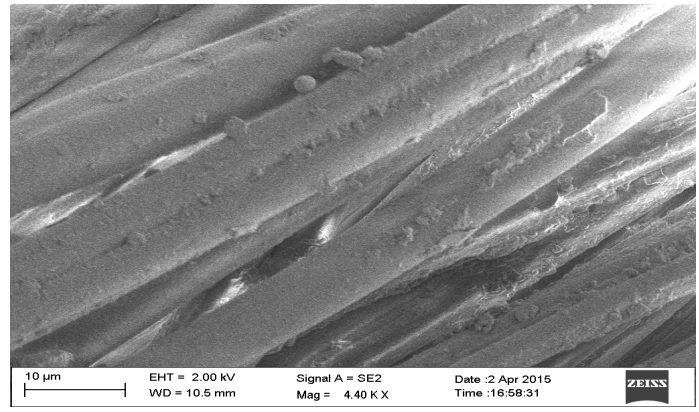

1-d. CSN treated \& RSW dyed silk fabric

Fig.1. SEM images of the silk fabric

\subsection{Study from the XRD-graph of the PAD and CSNtreated silk fabric}

The XRD graphs of silk fabrics applied with PAD and CSN (2-a, 2-b) treatments followed by dyeing with natural dye - RSW (2c, 2d) respectively are given in the Figure-2. These figures reveal about the effect of respective PAD and CSN treatments on the silk fabrics. When the silk fabrics are subjected with PAD and CSN (2-a, 2-b) followed by dyeing with RSW (2-c and 2-d); the bandwidth of the XRD graph is in a increased trend which gives the information about the effect of treatment of PAD and CSN on the mulberry silk fabric sample. Normally $\mathrm{X}$-ray diffraction study is done in a common textile materials for the effective characterization in the identification of crystal orientations and inter-atomic spacing. The characteristically generated $\mathrm{x}$-ray diffraction pattern gives a unique fingerprint of the respective crystals present in the sample are quite common in the typical XRD analysis. The generated fingerprint favors the identification of the respective crystalline arrangement when compared with those of the standard reference patterns and measurements. $(38,39)$. 


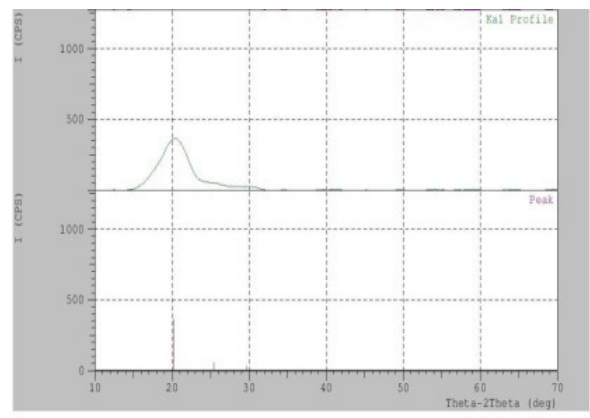

2-a. PAD treated silk fabric

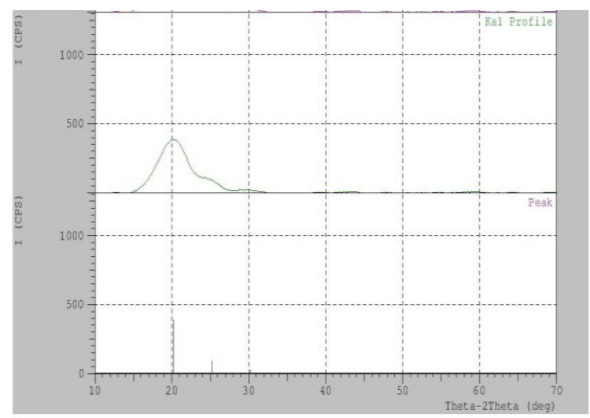

2-b. CSN treated silk fabric

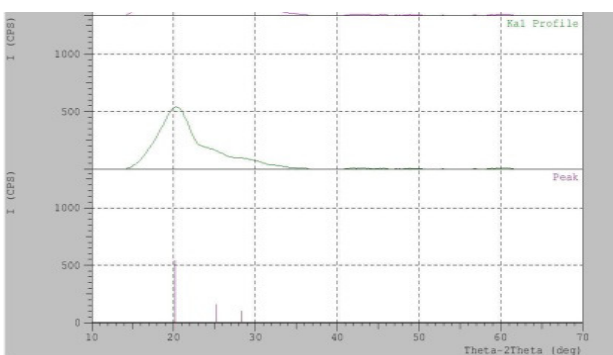

2-c. PAD treated \& RSW dyed silk fabric 


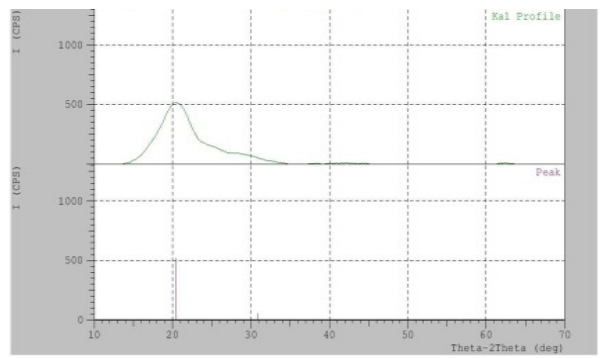

2-d. CSN treated \& RSW dyed silk fabric

Fig. 2 XRD graphs of the silk fabric

\section{Conclusions}

The following conclusions are arrived from this research work; the required textile physical properties of the PAD treated and CSN treated silk fabrics are in the considerable higher track needed for the product protection. The collective color value-k/s and related properties for fastness behavior needed for the PAD and CSN treated dyed silk fabrics are good in a significant manner. The important textile comfort/aesthetic behaviors based on absorbency (drop-absorbency, water-retention, wicking, permeability(water and air)) characteristics present in the PAD and CSN treated and dyed silk fabrics are in the neat track required for the end product comforts. The PAD and CSN treated and dyed (natural \&synthetic) silk fabric show a remarkable anti-odor effect. Additionally, these silk fabrics show improved anti-odor retention behavior and the respective anti-odor release rate applicable to the garment and likewise textile products in the quality way. Finally, these effects are well confirmed by the SEM images and the XRD graphs.

\section{Acknowledgement}

We express our thanks \& gratitude to the Principal \& the Management - PSG College of Technology, Coimbatore for allocating the required facilities. Thanks are also due to The Research \& Development Centre; and the Department of Chemistry, Bharathiar University, Coimbatore for the kind help and support.

\section{References}

[1] Teli, MD, Kartick, K, Samanta, Pintu, P, Basak, S, and Chattopadhyay, SK. Lowtemperature Dyeing of Silk Fabric Using Atmospheric Pressure Helium/Nitrogen Plasma, Fibers and Polymers 16: 2375-2383, 2015. 
[2] Currie, R. Silk, Mohair, Cashmere and Other Luxury Fibers, Ed.: Franck, R.R., 1-67, Woodhead Publishing Ltd, England, 2001.

[3] Morton, WE, andHearle, JWS. Physical Properties of Textile Fibres, 274-321, Woodhead Publishing, Textile Institute, Manchester, England, 2008.

[4] Padaki, NV, Das, B, and Basu, A. Advances in Silk Science and Technology, Ed : Basu, A. 3-16, Woodhead Publishing Ltd. England, 2015.

[5] Needles, HL. Textile Fibers, Dyes, Finishes and Processes: A Concise Guide, Noyes Publications. Park Ridge, N.J., USA, 1986.

[6] Matsudaira, M., and Kawabata, S. A Study of the Mechanical Properties of Woven Silk,Fabrics, Part 1, Fabric Mechanical Properties and Handle Characterizing Woven Silk Fabrics, The Journal of Textile Institute, 79 (3), 458-475, 1988.

[7] Nurkeeva, ZS, Khutoryanskiy, VV, Grigoriy, MA, Sherbakova, MV, Ivaschenko, A, and Aitkhozhina, TNA. Polycomplexes of poly(acrylic acid) with streptomycin sulfate and their antibacterial activity, European Journal of Pharmaceutics and Biopharmaceutics. 57 (2), 245249, 2004.

[8] Prakip, KD, Joydeep, D, Tripathi, VS. Chitin and chitosan properties and application, Journal of Scientific and Industrial Research, 63: 20 - 31, 2004.

[9] Marguerite, R. Chitin and chitosan: Properties and applications, Progress in polymerScience, 31: 603-632, 2006.

[10] Yang, HC, Wang, WH., Huang, KS. Preparation and Application of Nanochitosan to Finishing Treatment with Anti-microbial and Anti-shrinking Properties, Carbohydrate Polymers, 79: 176-179, 2010.

[11] Sargunamani D, Selvakumar N. Degumming of Silk - A Review. Colourage 49(3), 43-48, 2002.

[12] Moses, JJ, Mariappan, A, \&Vellingiri, K. A Study on Silk and Its Mixed Fabric for TheirFunctional Properties, Walailak Journal of Science \& Technology, 13(11), 913-922, 2016.

[13] Qinwei Gao, Zhengzhong Shao, YuyuSun, Heng Lin. Complex Formation of SilkFibroin With Poly(acrylic acid). Polymer Journal 32(3), 269-274, 2000.

[14] InmaculadAranaz, Marian Mengibar, Ruth Harris, Inés Panos, Beatriz Miralles, Niuris Acosta, Gemma Galed, Ángles Heras. Function characterization of Chitin and Chitosan. Current chemical Biology 3, 200-230, 2009.

[15] Vellingiri L, Ramachandran T, Senthilkumar M. Eco-Friendly Application of Nano Chitosan in Antimicrobial Coatings in the Textile Industry. Nanoscience andNanotechnology, 3(4), 75-89, 2013.

[16] Vipin Bansal, Pramod Kumar Sharma, Nitin Sharma, Om Prakash Pal, RishabhaMalviy. Applications of Chitosan and Chitosan Derivatives in Drug Delivery. Advances in Biological Research 5(1), 28-37, 2011.

[17] Brossman R, Kleinemeier N, Krayer M, Oesch HP, Groebel BT, Kuehni R, Leaver AT. Determination of Relative Color Strength in Solution. Journal of Society of Dyers and Colourists 1, 38-42, 1987.

[18] Perkins WS. Review of Textile Dyeing Processes. Textile Chemist and Colorist 8, 23-27, 1991.

[19] BIS Test Method IS:764-1979, Test 3, Indian Standard Method for Determination of Color Fastness of Textile Materials to Washing, Bureau of Indian Standards, 1979.

[20] AATCC Test Method 16E-2004, Color Fastness to Light. Technical Manual of the AATCC, Research Triangle Park, USA, 2004.

[21] AATCC Test Method 8-2007, Color Fastness to Crocking. Technical Manual of the AATCC, Research Triangle Park, USA, 2007.

[22] Young-Hee Lee, Han-Do Kim, Dyeing Properties and Color Fastness of Cotton and Silk Fabrics Dyed with Cassia Tora L. Extract. Fibers and Polymers 5(4), 303-308, 2004.

[23] Hojo, N. Structure of Silk Yarn - Part B - Chemical Structure and Processing of Silk Yarn. Science Publishers Inc, Enfield, USA 135-157, 2000. 
[24] Handbook of Fiber Chemistry, Menachem Lewin, Editor, 3rd ed, CRC Press, Gleason, Carrie, The Biography of Silk. Crabtree Publishing Company. 12, 2006.

[25] AATCC Test Method 79-2010, Absorbency of Textiles, Technical manual of the AATCC, Research Triangle Park, USA, 2010.

[26] AATCC Test Method 21-1978. Analytical Methods for a Textile Laboratory, Third Edition, Ed. J. William Weaver, University of Delaware, AATCC, Research Triangle Park, USA, 1984.

[27] AATCC test method 197-2013, Vertical Wicking of Textiles, Technical Manual of the AATCC, Research Triangle Park, USA, 2018.

[28] ASTM - E96- 2000, Standard Test Methods for Water Vapor Transmission of Materials, ASTM International, 100 Barr Harbor Drive, PO Box C700, West Conshohocken, PA, 194282959, USA, 2000.

[29] ASTM - D737-2012, Standard Test Methods for Air Permeability of Textile Fabrics. ASTM International, 100 Barr Harbor Drive, PO Box C700, West Conshohocken, PA 194282959,USA, 2012.

[30] Anjali Karolia, Snehal Mendopara. Imparting Antimicrobial and Fragrance Finish on Cotton Using Chitosan with Silicon Softener. Indian J of Fiber \& Textile Res 32, 99, 2007.

[31] Purwar R, Joshi M. Recent Developments in Antimicrobial Finishing of Textiles-A Review. AATCC Review 4, 22-26, 2004.

[32] Beane, Rachel, Using the Scanning Electron Microscope for Discovery Based Learning in Undergraduate Courses. Journal of Geoscience Education 52(3), 250-253, 2004.

[33] JeyakodiMoses, J. Venkataraman VK. Study of K/S, Antibacterial, UV-Protection, Anti-Odor and SEM on Chemical Treated Cotton Fabrics. Journal of Engineered Fibersand Fabrics 12, 39-49, 2017.

[34] Klug HP, Alexander LE. X-Ray Diffraction Procedures for Polycrystalline and Amorphous Materials. 2nd ed. Wiley, New York, 1974.

[35] Sujatha Sampath, Thomas Isdebski, Janelle E. Jenkins, Joel V. Ayon, Robert W. Henning, Joseph PRO, Orgel, Olga Antipoa, and Jeffery L. Yarger. X-Ray Diffraction Study of Nanocrystalline and Amorphous Structure Within Major and Minor Ampullate Dragline Spider Silks. Soft Matter 8(25), 6713-6722, 2012.

[36] Hearle, JWS. Use of the Scanning Electron Microscope, Pergamon Press, Oxford, London, 1972.

[37] Patel, GS, Bhama, P, Sreenivasan, S, and Krishna, KR. Reversals in Cotton: A Study With Scanning Electronmicroscopy, Textile Research Journal, 60, 771$774,1990$.

[38] Oh, SY, Yoo, DI, Shin, Y, Kim, HC, Chung, YS, Park, WH, \&Youk, JH. Crystalline Structure Analysis of Cellulose Treated with Sodium Hydroxide by Means of X-ray Diffraction and FTIR Spectroscopy”, Carbohydrate Research, 340(15): 2376-2391, 2005.

[39] Mitcham, D, Berni, RJ, and Tripp, VW. An X-ray Diffraction Method for the Analysis of Cotton/Polyester Blends, Textile Research Journal, 47, 386-388, 1977. 